\title{
Análise Colorimétrica de Berinjela e Pera Irradiadas com Fonte de Co-60 em Atmosfera com e sem a Presença de Oxigênio
}

\author{
Scolforo, C. Z. ${ }^{1}$, Gazolla, G. T. ${ }^{2}$, Rosa, N. A. B. ${ }^{2}$, Passamai, J. L. Junior ${ }^{3}$, Pinheiro, C. J. \\ $\mathrm{G}^{3}$, Della Lucia, S. $\mathrm{M}^{2}$. \\ ${ }^{1}$ Ciência e Tecnologia de Alimentos, Campus Alegre /UFES Universidade Federal do Espírito Santo, ES, Brasil \\ ${ }^{2}$ Departamento de Engenharia de Alimentos, Campus Alegre/UFES \\ ${ }^{3}$ Departamento de Química e Física, Campus Alegre - UFES
}

\section{Resumo}

A irradiação de alimentos usando radiação ionizante é um método direto de conservação de alimentos. Por via indireta, a radiação ionizante provoca a formação de radicais livres, no oxigênio presente no ar do ambiente $\left(\mathrm{O}^{\circ}\right)$, gerando ozônio $\left(\mathrm{O}_{3}\right)$, e na água presente nos alimentos $\left(\mathrm{OH}^{-}\right)$, gerando peróxido de hidrogênio $\left(\mathrm{H}_{2} \mathrm{O}_{2}\right)$. Neste trabalho foram irradiados amostras de berinjela e pera com radiação gama, proveniente de uma fonte de Cobalto-60 (CDTN/CNEN), nas doses de 0 kGy, 1 kGy e 4 kGy. As amostras foram acondicionadas em embalagens opacas abertas e embalagens opacas a vácuo. O trabalho teve como objetivo verificar os efeitos indiretos produzidos pela radiação ao dissociar moléculas de oxigênio. Foram realizadas análises colorimétricas de acordo com a escala CIELAB nas polpas e cascas das amostras e calculou-se a diferença global de cor. Os resultados indicam que a ausência do $\mathrm{O}_{2}$ influenciou na alteração perceptiva da cor nas doses estudadas tanto na polpa quanto na casca ao serem comparadas com a amostra controle (0 kGy). Portanto, ao se irradiar berinjela e pera nessas doses recomenda-se retirar o ar das embalagens.

Keywords (Palavras chaves): Radiação ionizante, Irradiação de Alimentos, Oxidação.

\section{Introdução}

As radiações ionizantes têm diversas aplicações nos dias de hoje, tornando-se parte do cotidiano da humanidade. Elas surgem quando os núcleos de átomos, que se encontram em um nível energético superior e instável, emitem partículas ou ondas eletromagnéticas energéticas, passando para um nível de energia menor, tornando-se estáveis. As partículas emitidas são alfa, beta e nêutrons. No caso da emissão de energia, elas ocorrem na forma de onda eletromagnética, raios gama.

O processo de ionização ocorre quando a radiação ionizante interage com a matéria, arrancando elétrons da órbita atômicas. O resultado é um elétron livre de alta energia e um íon positivo ou um radical livre, quando ocorre a quebra de uma ligação química.

O cobalto-60 (Co-60) é um tipo de radioisótopo natural produzido por meio de uma reação nuclear na qual o isótopo cobalto-59 estável, é bombardeado com nêutrons no interior de um reator nuclear, transformando-se no isótopo Co60, instável e radioativo. Durante o seu decaimento são emitidos dois raios gama com energias de 1,17 e 1,33 MeV [1,2].

$A$ radiação gama, utilizada como radiação ionizante no bombardeamento de produtos alimentícios, é usada para esterilizar ou desinfestar produtos, ou então provocar alguma alteração genética em organismos vivos.

Os raios gama penetram instantaneamente $\left(10^{-}\right.$

${ }^{16}$ s) os materiais, desde substâncias líquidas até concreto, ionizando orbitais atômicos, destruindo microrganismos ou alterando a estrutura celular primária. Estes raios usados na irradiação de alimentos é um método direto de conservação dos mesmos. Por via indireta, a radiação gama provoca a formação de radicais livres, no oxigênio do ar atmosférico ( $\left.\mathrm{O}^{-}\right)$, gerando ozônio $\left(\mathrm{O}_{3}\right)$. Esses radicais são altamente reativos e interagem com componentes vitais dos micro-organismos causando danos letais de forma indireta $[1,3]$. 
A luz é uma radiação eletromagnética na faixa do visível, onde seu intervalo de frequência varia em cores desde o violeta até o vermelho. A cor é uma percepção visual resultante da detecção da luz após interação com um objeto. O impacto visual gerado pela cor, sobrepõe-se, frequentemente, ao causado por outros atributos de aparência e odor.

O objetivo deste trabalho foi verificar alterações na cor, das amostras de berinjela e pera irradiadas, devido os efeitos indiretos produzidos pela radiação gama, ao dissociar moléculas de oxigênio durante o processo de irradiação de alimentos.

\section{Metodologia}

Neste trabalho foram irradiadas amostras de berinjela e pera com radiação gama, proveniente de uma fonte de Cobalto-60 do Laboratório de Irradiação Gama do CDTN (LIG/CDTN/CNEN). As amostras foram acondicionadas em embalagens opacas abertas (sistema aberto) e embalagens opacas a vácuo (sistema fechado) e divididas em controle (0 kGy) e irradiadas com doses de 1 kGy e 4 kGy.

A análise colorimétrica realizada, com auxílio de um colorímetro (Espectrofotômetro CM-5), onde a amostra irradiada foi comparada com a de controle (OkGy) diferenciando os sistemas fechados e abertos.

Para melhor apresentação e visualização de resultados foi realizado segundo o espaço de cor CIELAB, com sistema tridimensional onde $L^{*}$ luminosidade (do preto ao branco), $a^{*}$ que consiste no eixo que varia do vermelho, mais positivo, ao verde, mais negativo, $b^{*}$ varia do amarelo, mais positivo, ao azul, mais negativo, $h$ (ângulo de tonalidade cromática) e $c^{*}$ saturação de cor [7]. O cálculo da diferença absoluta $(\Delta E)$ de $L$, a e b em relação ao padrão usa a equação

$\Delta \mathrm{E}^{*}=\sqrt{\Delta \mathrm{L}^{2}+\Delta \mathrm{a}^{2}+\Delta \mathrm{b}^{2}}$.

\section{Discussão}

Prandl, 1994, afirma que, quando o $\Delta \mathrm{E}$ resultar acima de 5 , houve uma diferença perceptível a olho nu na coloração da amostra e acima de 12 implica em diferença de cor absoluta [7]. Com isso podemos afirmar que tanto a berinjela quanto a pera nos sistemas aberto e fechado tiveram notória perda de cor.

No sistema aberto para as doses de 1 e 4 kGy a berinjela teve seu $\Delta \mathrm{E}$ de 12,9 e 8,6 , respectivo as doses. Para a pera $\Delta \mathrm{E}$ variou de 10,4 (1 kGy) a 9,3 (4 kGy). No sistema fechado para as doses de 1 e $4 \mathrm{kGy}$ a berinjela teve seu $\Delta \mathrm{E}$ de 6,7 e 3,8 , respectivo as doses. Para a pera $\Delta E$ variou de 4,7 (1 kGy) a 5,0 (4 kGy).

Conclui-se então com base nos resultados que amostras irradiadas podem ter alterações significativas ao serem tratadas em diferentes ambientes. A embalagem a vácuo obteve menor diferença. $\mathrm{Na}$ embalagem opaca aberta houve contato com o ar atmosférico permitindo uma degradação de pigmento, devido a presença dos radicais livres produzidos, na dissociação das moléculas de oxigênio $\left(\mathrm{O}^{\circ}\right)$, gerando ozônio $\left(\mathrm{O}_{3}\right)$, na interação de radiação gama por via indireta.

\section{Agradecimentos}

Agradecemos ao LIG/CDTN/CNEN.

\section{Referências}

[1] Rela, P. R. Revista da SBCC, ed 4, 2001.

[2] Calvo, W. A. P. Desenvolvimento do Sistema de Irradiação em um Irradiador Multipropósito de Co-60 do Tipo Compacto. Dsc. IPEN/SP, 2005.

[3] Uzeli, D. H. Estudo Sobre o Gás Ozônio Formado no Processo de Irradiação Industrial com Cobalto-60 e seu Impacto no Meio Ambiente. IPEN, São Paulo, 2013.

[4]www.fao.org/inpho_archive/content/document s/vlibrary/ae620s/pfrescos/BERENJENA.HTM.

[5] ANTONIOLLI, L. R. Pera: perspectivas de produção e conservação pós-colheita. Simpósio de Pós-colheita de frutas, hortaliças e flores. 3 ed., RJ: Embrapa, 2011.

[6] CANER,C., \& ADAY,M.S. Maintaining quality of fresh strawberries though various modified atmosphere packaging. Packaging Technology and Science, v.22, p. 115 - 122, 2009.

[7] PRANDL, O. et al., Tecnología de Hyhiene de la Carne. Zaragoza: Acribia, 1994. 